\title{
Transpersonale onderwys van die New Age- beweging: 'n evaluering en perspektiefstelling
}

Jeannette Steyn

Departement Opvoedingswetenskappe

Vaaldriehoekkampus van die $\mathrm{PU}$ vir $\mathrm{CHO}$

VANDERBIJLPARK

\begin{abstract}
Afier analysing Transpersonal Education as a view espoused by the New Age, the conclusions reached were that

* Transpersonal liducation is a spiritual event, an experience of a new awareness characterised by the incarnation of the sacred; further.

* the teacher should bring about this awareness in the child by spiritual transformation through karma, darma and rituals such as yoga and meditalion.

According to this school of thought self-actualization stimulates the power in oneself and unleashes dark forces deep inside the soul. This point of view inplies human autonomy and the power to govern human affairs by the human spirit. It is therefore an inevitable conclusion that Transpersonal Education as the view of the New Age accentuates the spiritual character of man and therefore minimizes the other functions of man, so that Transpersonal Education can not be regarded as anything other than educationally unbalanced and Scripturally unsound.
\end{abstract}

\section{Inleiding}

Sedert die sestigerjare van hierdie eeu was daar 'n duidelike verskuiwing vanaf die beklemtoning van dic meer rasionele benadering in die onderwys (vergelyk strominge soos die Sciëntisine en Neo-idealisme) na die meer irrasionele of gevoel van die mens (vergelyk die Neo-humanisme) (Steyn, 1990; Venter, 1991: 61). Die kern van menswees is vir die rasionalis die mens se verstandelike vermoëns en vir die irrasionalis die vermoë tot gevoelsbelewing. Die New Agers stel egter die hoër geestelike vermoëns van die mens as sy diepste kern.

Schaeffer wys reeds in 1972 daarop dat daar 'n duidelike klem op die hoër geestelike vermoëns ontwikkel het as gevolg van die invloed van Oosterse godsdienste. Hy voorspel ook daarmee dat dié ontwikkeling teen 1980 duideliker na 
Transpersonale onderwys van die New Age-bew'eging

vore sal tree (Schaeffer, 1972). So ontwikkel die New Age-beweging (voortaan $\mathrm{NAB}$ ), ook bekend as die global approach. In Oktober 1979 kry ons die eerste reaksies van opvoedkundiges, onder andere met ' $n$ lesing in kurrikulumkunde wat gelewer word deur Elliott Seif te Minneapolis: "Dare We Build a New Curriculum for a New Age?" Verskeje New Age-boeke vir onderwys in skole verskyn (Matriano, 1987; Jenkinson, 1988), sowel as pleitredes vir die verandering van die onderwysbenadering met 'n sterker klem op die hoër geestelike vermoëns van die mens. Ferguson (1987) noem hierdie benadering transpersonale onderwys (kyk par. 3.1).

Eers vanaf ongeveer 1985 het die NAB in Suid-Afrika na vore getree (Van der Walt, 1990:2-4). Die feit dat die Oosterse godsdienste soos die Hindoeïsme, Boeddhisme, Taoïsme (Van der Walt, 1991:2) en ook die Westerse okkultisme of Satanisme (Pypers, 1990:7; Steyn, 1992:16) al hoe meer veld gewen het in SuidAfrika, het die groeibodem vir die NAB voorberei. (Die NAB kan beskou word as 'n sinkretisme van genoemde godsdienste.) Dit het daarom noodsaaklik geword dat daar ook vanuit die Opvoedkunde krities na die NAB gekyk moet word

Die fokus van hierdie artikel is die evaluering van transpersonale onderwys (volgens die New Age) vanuit 'n Skriftuurlike benadering.

Die doelstellings van die NAB sal eerstens uiteengesit word, waarna die algemene kenmerke van die NAB in die onderwys uitgesonder sal word. Daarna sal die kenmerke vergelyk word met 'n Skriftuurlike benadering in die onderwys. Daar word, met ander woorde, gebruik gemnak van probleem-historiese, perspektiwiese en vergelykende metodes in hierdie artikel.

\section{Hoofgedagtes van die NAB}

Die aanhangers van die NAB glo dat die mens, kosmies en astrologies bepaald, aan die begin van 'n nuwe tydperk in die geskiedenis staan. Die 'polariserende' tydperk van die Clristendom of die Pisces (visse volgens die sterre) is besig om verby te gaan en die mens betree die 'harmoniserende' tydperk van Aquarius (die waterman). Die tydperk van die Pisces was 'n tyd van vaste waardes en sekerhede - 'n tydperk waarin die verstand van die mens, die tegnologie en die bewysbaarheid deur die natuurwetenskappe 'n groot rol gespeel het. Die NAB wil die geestelike mag van die mens transformeer in 'n universele, superspiritualiteit.

Die mens self is volgens die $\mathrm{NAB}$ outonoon en nie meer tevrede met die gewone denkrigtings (waaronder die Christendom) wat geen verandering meegebring het nie; daarom hierdie strewe en gebruikmaking van verskillende godsdienste om spiritualisties van die aarde af gelig te word. Indien die mens so 'n fase kan 
bereik, kan daar versoening van alle mense op aarde kom, kan 'n global community of 'universele samelewing' tot stand kom.

Om ' $n$ idee te kry van die invloedsfeer en gedagterigting van die NAB, kan kortliks gelet word op die vier vlakke waarop die NAB funksioneer (vlakke geïdentifiseer deur Spangler, 1984:78-83). Die eerste vlak is die oppervlakkige toestand waarin die mens op ekonomiese en kommersiële gebied uitgebuit word: klere, kos en selfs standplase word verkoop met die benaming en etikettering van die New Age. Die tweede vlak van NAB-betrokkenheid is 'n uitlewing van die fantasie, betowering en okkultiese bedrywighede. (Hierdie tweede beïnvloedingsvlak behoort, in die bekamping van die NAB-doelwitte, die meeste aandag te kry.) In Suid-Afrika bestaan daar 'n kombinasie van die eerste en tweede vlakke in dié sin dat advertensies in dagblaaie mense dikwels aanspoor om gebruik te makk van rubrieke soos "Die sterre voorspel", die dienste van mense soos tarotkaartlesers en verskillende aspekte van goëlary om hulle toekoms te voorspel. Dié uitnodigings is dan verbind aan telefoomnommers wat geld invorder om hierdie dienste te lewer

Die derde vlak word gekenmerk deur die beeld van 'n veranderde wêreld: die mens bevraagteken die bestaande dominering van die Westerse wêreld en is op soek na 'n nuwe wêreldvisie. Die vierde vlak verteenwoordig die werklike kern van die $\mathrm{NAB}$ en behels die wedergeboorte van die geestelike bestaan van die mens. Volgens Spangler (1984:82) is die NAB op dié vlak 'n geestelike belewing en poog dit om in kombinasie met die derde vlak, die doel van die stroming te bereik, naamlik

deepening of the sacramental nature of everyday life, and awakening of the consciousness that can celebrate divinity within the ordinary and, in this celebration, bring to life a sacred civilization.

\section{Algemene onderwyskenmerke van die NAB}

\subsection{Die wese van die NAB-onderwys}

Volgens Matzken (1990:130-131) is die NAB-onderwys gerig op die ontwikkeling van 'n nuwe mens wat 'n nuwe tydperk moet betree. Om 'n 'nuwe mens' te laat ontwikkel word gebruik gemaak van 'n transpersonale benadering in die onderwys. Trans of transisie beteken 'n oorgang of verwisseling. Die oorgang kom tot stand deur die klemverskuiwing vanaf die mens se verstand of gevoel na die hoër geestelike vermoëns van menswees (vergelyk par. 1).

Ferguson (1987) stel dan dat transpersonale onderwys die leerling aanspoor om outonoom te funksioneer, 'n kritiese ingesteldheid te ontwikkel, 'n diepteondersoek te rig op die bewustelike ervaring van die mens, die sin van die lewe te 
Transpersonale ondenwys van die New Age-beweging

ondersoek en laastens om tot die uiterste te gaan in die soeke na die eie ek (vergelyk ook Matzken, 1990:134)

\subsection{Die doel van die NAB-onderwys}

Die hoofdoel van dié onderwys is volgens die NAB die verwesenliking van die self. Vanweë die siening van die NAB dat alles een is, naamlik God, mens en werklikheid (panteïsme), beteken dit ook dat alles en almal gelykwaardig is Selfverwesenliking beteken dus nie lewe net vir die self nie, maar impliseer ' $n$ holistiese wyse van ontwikkeling van die onpersoonlike, geestelike ek wat moet opgaan in hoër werklikhede as die aardse. Dié doelstelling kan alleen bereik word deur spesifieke metodes soos joga te gebruik (Ferguson, 1987:292-293; Jenkinson, 1988).

'n Verdere doelstelling is dat die onderwyser die kind moet lei om af te sien van die ou bedeling (tydperk van die vis) sodat global citizenship ('n universele samelewing) bekom kan word. Die onderwys moet getransformeer word om meer op die geestelike te konsentreer. Bewussynsverruiming moet nagestreef word (Dreckmeyr, 1991:13; Hahn, 1984:242).

Dié doelstelling het nie slegs betekenis vir die manipulering van inligting nie, maar ook vir die ontwikkeling van die aktiwiteite van die regter- en linkerbrein (vergelyk 3.3). Die NAB beskou die tydperk waarin ons leef as 'n beweging vanaf die industriële na die inligtingstydperk. Dit is egter nie nodig vir die mens om 'n feitemasjien te wees nie, maar hy moet oor die denkvaardighede beskik om inligting te bekom en te manipuleer. Indien hy inligting kan manipuleer, kan hy die regter- en linkerbreinhelftes (wat kreatiwiteit insluit) inspan om die hoër geestelike aktiwiteite te beheer (Ferguson, 1987:298; Chance, 1986:4; Dreckmeyr, 1991:9)

Die leerling moet aangemoedig word om homself te ontdek, van buite en van binne. Selfontdekking bring bewussynsverruiming en lei tot outonomie (die maak van eie wette). Slegs deur sy eie god te wees (outonomiteit), kan hy transendeer (die bo-sintuiglike ervaar). Outonomie bring ook werklike vryheid van eksterne invloede wat hom wil manipuleer (Venter, 1991:54; Van der Walt, 1991:23).

\subsection{Die inhoud van die NAB-onderwys}

Die volgende moet volgens die NAB ingesluit word by die kurrikulum:

* liggaamlike opvoeding sodat die kind sy fisiese bestaan kan beheers (veral deur middel van joga, ontspanningsoefeninge, NAB-musiek en meditasie),

* vitale opvoeding vir die ontwikkeling van die sintuie, 
* mentale opvoeding sodat beheer oor konsentrasie en gedagtes verkry kan word,

* psigiese opvoeding vir die ontdekking van darma (die weg en pligsvervulling) en karma (deelname en aktiewe handeling),

* geestelike opvoeding, sodat die kind kan transendeer of vlug uit die alledaagse na die geestelike (Ferguson, 1987).

Die klem moet verskuif word van die tradisionele aanleer van soveel feite as moontlik (inhoud) na die konteks van feite. Die klemplasing op die konteks van die feite impliseer die betekenis van sekere feite, die wyse waarop inligting bekom kan word en hoe die inligting beheers kan word deur die uitoefening van kritiek (Ferguson, 1987:289)

Die kurrikulum moet volgens die NAB so saamgestel word dat 'n universele gemeenskap moontlik is; daarom 'n global curriculum. Dit is egter onmoontlik dat alles in die skool geleer kan word en daarom sluit die NAB-beskouing van 'alles is een' of holisme, die totale samelewing as onderriggewers van die leerder in (Chance, 1986:7; Halın, 1984:242).

\subsection{Die onderrigmetodes van die NAB-onderwys}

Pellettiri het reeds in 1977 transpersonale psigologie voorgestel vir die ontwikkeling van skryftegnieke in enige taal. Dié tegnieke behels innerlike bewuswording, ontspanningsoefeninge, meditasie, linker- en regterbreinlob-stimulering en geestelike transendering. Inligting oor die leerling se geboorte, lewe en toekomstige voorspelde lewe kan volgens hom help om innerlike bewuswording tot die hoogste vlak van geestesbewussyn te laat ontwikkel.

$\mathrm{Na}$ aanleiding van die Sjinese Taoïstiese yin-yan-beginsel waardeur manlike eienskappe inbegrepe is by vroulike eienskappe, ontwikkel die linker- en regterbreinlobteorie wat veral in die onderwys opgang maak. Dié teorie impliseer dat die linkerbreinlob die rasionele, liniêre (feitelike) denkwyses verteenwoordig, terwyl die regterbreinlob die vreedsame, universele en kreatiewe denkwyses verteenwoordig. Daar word beweer dat dit juis die regterbreinlob is wat tot dusver afgeskeep is en van die mens slegs denkende robotte gemaak het. Verskeie metodes word dan deur die NAB ontwikkel waarin die regterbreinlob 'gestimuleer' word sodat daar beter in die moderne tyd gefunksioneer kan word. Indien die stimulering suksesvol is, verseker dit dat die brein 'holisties' as 'n eenheid funksioneer. Die stimulering lei tot transendering en die makliker konsentrering op oefeninge soos joga en meditering (Venter, 1991:55; Van der Walt, 1991:19).

Om bokant jou liggaam te kan uitstyg, is die ontdekking van jou liggaamlike self noodsaaklik en primêr. Daarna kan joga, meditasie, die opsê van die mantras, 
spiritisme (oproep van geeste) en toekomsvoorspelling bydra tot bewussynsverruiming en die beweging van die gees na die transendentale. Die NAB praat dan ook van 'n transpersonal life of transpersonale karakter (Ferguson, 1987:315; Van der Walt, 1991:22-23; Dreckmeyr, 1991:16)

In die klaskamer is teoretiese en abstrakte kennis volgens (Ferguson (1987:290) nutteloos as die kennis nie aangevul word deur eksperimente binne en buite die klaskamer nie. Verder moet daar ook gebruik gemaak word van spesialiste uit die samelewing vir die praktiese demonstrasies en deurgee van inligting.

\subsection{Die onderwyser van die NAB-onderwys}

Daar word na die Maitreya van die Hindoeïstiese godsdiens verwys as die world teacher van die NAB. Die Hindoeïste wys egter daarop dat enige godsdiens maar kan glo in sy godheid omdat alle gode universeel is - die gode word net verskillend benoem (weer eens die glohal approach). Dié beskouing vorn deel van die Panteïsme (alles is god) en Spiritualisme (alles is geestelik). Die world teacher se hulp moet ingeroep word om die mens bewus te maak van sy volle goddelike potensiaal (Van der Walt, 1991:24).

Die tradisionele onderwyser (eksterne leraar) moet volgens die NAB verdwyn om plek te maak vir die intene leraar of die kind self. Dit beteken dat die onderwyser die leerling die vryheid moet bied om sy eie werklikheid te skep, 'n openheid om nuwe moontlikhede te ontwikkel en on verbande of patrone te kan insien. Die onderwyser se taak is om te weet wanneer hy die leerling moet laat 'worstel' en wanneer hy hom vrye teuels moet gee sodat hy sy weg na herskepping of transformasie kan ontwikkel (Ferguson, 1987:292; Dreckmeyr, 1991:16).

\subsection{Die leerling en die skool vanuit die NAB-onderwysperspektief}

Volgens die NAB-antropologie bestaan die mens slegs as 'n hoër geestelike wese - juis daarom moet die NAB-onderwyser poog om die leerling deur transpersonale onderwys te laat ontwikkel. Volgens die NAB bring ' $n$ transpersonale onderwysbenadering die volgende veranderinge teweeg:

* die mens se bewussyn en denkpatrone word verander;

* die mens rig homself op reïnkarnasie, slegs sy karma en darma kan bepaal in watter vorm hy sal terugkeer na die aarde;

* 'n mistiese wetenskap word op die been gebring;

* die mens word 'n mistieke deel van die werklikheid;

* die mens word gerig op innerlike outoriteit; 
* die ontwikkeling van die holistiese brein word 'n voorvereiste;

* die mens strewe na die sin en doel van die lewe wat bo die aardse werklikheid is (Ferguson, 1987; Dreckmeyr, 1991; Van der Walt, 1990).

Reïnkarnasie vorm vir die NAB 'n deel van die transmigrasieleer wat weer verbind is aan die evolusionisme. Die betekenis hiervan is dat daar op die pad vorentoe altyd verbetering en vooruitgang sal wees. Die mens se karma (aktiewe handeling en deelname) sowel as sy darma (pligsvervulling), bepaal sy reïnkarnasie-gestalte (Venter, 1991:56; Van der Walt, 1991:24).

Volgens Burback (1987:3) moet die skool die hoofkern word waaromheen die toekoms van die mens se eteriese bestaan ontwikkel word. Slegs die skool kan volgens hom die inisiatief neem "in changing, shaping and defining education's role".

Die NAB benodig volgens Ferguson (1987:289) nie die skole om sy beginsels uit te dra nie, maar die skole het 'n beloefte aan transpersonale onderwys. Die enigste stremmende faktor wat meebring dat die onderwys nie vinnig kan verander na transpersonale onderwys nie, is volgens hom ekonomiese faktore, die bestaande stelsel en die mens se onwilligheid om in te stem tot vernuwing.

\section{Die NAB-onderwys teenoor 'n gebalanseerde en Skriftuurlik- getroue onderwysbenadering}

\subsection{Die wese van die onderwys (vergelyk 3.I)}

Die NAB verwys na 'n 'nuwe' geestelike tydperk en 'n 'nuwe' geestelike mens terwyl die Skrif aandui dat die eindtyd voorafgegaan word deur die mens se soeke na sy heil in deınone en ander magte bo homself (vergelyk 1 Tim. 4; 2 Pet. 2). Die rig op die hoër geestelike vermoëns van die mens bring ook noodwendig mee dat God ontken word en die mens self as godheid erken word. Vir die Christen-gelowige is sodanige uitgangspunt onaanvaarbaar.

Vir die Christen is die wese van die onderwys dat die kind opgevoed moet word om tot eer van God sy roeping uit te leef.

\subsection{Die doel van die onderwys (vergelyk 3.2)}

Die hoofdoel van die NAB, naamlik selfverwesenliking, as beperk tot die mens alleen, dui op 'n humanistiese benadering wat noodwendig beteken dat God uitgesluit word. Die Christen daarteenoor stel dat die mens opgevoed moet word tot eer van God en roepingsvervulling op aarde. So 'n benaderingswyse beteken die 
Transpersonale onderwys van die New Age-beweging

verwesenliking van die ingeskape moontlikhede en ontsluiting van Godgegewe potensiaal.

Die 'holistiese' doel van onderwys met die klem op die mens as geheelwese, is positief. Die skeeftrekking is egter weer eens dat dit slegs die holistiese $e k$ is wat moet ontwikkel tot transendering en dat enige hoër wese as die mens self ontken word.

Die NAB se klem op universaliteit kan positief wees in dié sin dat kerstening van die ganse mensdom tot die ware drie-enige God daardeur meegebring kan word Gelykwaardigheid wat deur sodanige doelstelling meegebring word, kan ook slegs positief wees indien dit in ooreenstemming is met God se Woord. Dié twee doelstellings bring egter mee dat die mens en die ganse skepping gesien word as goddelik (Panteïsme) en as geestelik (Spiritualisme). Hierdeur word die funksie van die mens om met die dieper geestelike dinge besig te wees oorskat deurdat hy self god word (in-aksie-stelling). Die ander funksies van die mens word dus afgeskeep - ' $n$ tendens wat noodwendig 'n ongebalanseerde benadering in die hand werk.

Bewussynsverruiming is positief indien dit tot eer van God aangewend word. Om egter bewussynsverruiming (insluitende ontwikkeling van die brein en manipulering van inligting) aan te wend om die mens in staat te stel om te transendeer na die hoër geestelike, beteken om weer eens die mens te verhef tot god en die kinderlike geloof in God Drie-enig en sy genade te ontbeer. Bewussynsverruiming verhef die mens tot god en impliseer dat die mens alles kan doen en alles kan beheer.

Die selfontdekkende strategie in die onderwys is 'n gebalanseerde didaktiese uitgangspunt indien dit aangewend word om die mens as geheelwese te ontwikkel Om egter daardeur outonomie as doelstelling voor te hou, bring die mens tot die gewaande illusie van goddelike beheersing oor die ganse skepping.

\subsection{Kurrikulum of inhoud (vergelyk 3.3)}

Dat daar vandag eerder gekonsentreer moet word op die metodes waarop inligting bekom kan word, as die memorisering van inligting, is waar. Die beheersingsfaktor van hierdie inligting deur die outonomie van die mens is egter nie moontlik nie. Die mens kan slegs 'n klein deeltjie van sy eie wêreld deur God se genade beheers.

Die liggaamlike, vitale, mentale, psigiese en geestelike onderwysinhoud wat deur die NAB-opvoeders daargestel wil word, is prysenswaardig. Die gebalanseerde aanwending van dié inhoudelike fasette is egter afwesig aangesien die hoogste doel die aanwending tot die getransformeerde persoonlikheid is. God het die 
totale mens geskape, dié mens wat opgevoed moet word tot beheersing van sy eie talente en vermoëns. Om te suggereer dat almal slegs tot getransformeerde persoonlikhede moet ontwikkel, is 'n ontkenning van die individualiteit van die mens.

\subsection{Metodes in die onderwys (vergelyk 3.4)}

Die Christelike uitgangspunt is dat 'n kombinasie van metodes aangewend moet word in die onderwys - 'n werkwyse waardeur die kind sy waardigheid as mens kan behou en kan aanwend tot eer van God.

Die yin-yang-beginsel bring noodwendig 'n dualistiese beskouing ten opsigte van die denkprosesse van die mens teweeg. Die mens funksioneer as 'n geheelwese en sodanige dualisme dui op 'n ongebalanseerde oorbeklemtoning van óf die een óf die ander. Die uiteinde van die oorbeklemtoning van die regterbreinlob moet vir die NAB egter 'n holistiese aanwending van die denkprosesse tot transendering meebring. Tog is daar deur die eeue bewys dat 'n oorbeklemtoning van die een noodwendig tot skeeftrekking sal lei (vergelyk die oorbeklemtoning van die gevoelsaspekte in Steyn, 1990).

Joga, meditasie en spiritisme hoort nie by die rituele van die Christenopvoeder nie, aangesien die metodes nie tot eer van God aangewend word nie. Om hierdie metodes in die skool te gebruik sou ook 'n pragmatiese wanbalans meebring aangesien slegs enkele leerlinge wel die gebruike sou bemeester en daarom die doel onvervuld laat. Dit bly ook 'n vraag of sodanige metodes wel die waardigheid van die mens in die oog het, aangesien die meeste metodes in werklikheid selfhipnose bewerkstellig en nie bewussynsvernuwing soos die NAB dit graag wil sien nie. Die Hara Krishna Hindoes beweer byvoorbeeld dat liefde vir die godheid opgewerk word deur bloot die mantras oor en oor te herlaal. Sodanige mantras verskaf dan 'n magiese krag wat niks anders as ' $n$ kondisioneringsproses is nie. Deur dié metodes te gebruik, kan daar nie van 'n Skriftuurlik-getroue mensbenadering sprake wees nie.

Die toepassing van teoretiese kennis deur eksperimentering buite en binne die klaskanner is van groot belang in 'n gebalanseerde benadering in die onderwys. Die standpunt van Ferguson (vergelyk 3.3) in hierdie verband is dus navolgenswaardig.

\subsection{Die onderwyser (vergelyk 3.5)}

'n Ware universele godsdiens bestaan nie, tensy die hele wêreld in God of dieselfde afgod begin glo. Die individualiteit van die mens en die gebrokenheid deur die sondeval maak dit egter onmoontlik dat daar 'n universele godsdiens kan bestaan. Universalisme lei ook noodwendig tot die opgaan van die individu in die 
groter geheel; in dié geval die groter goddelike en geestelike geheel. Die uiteinde beteken ' $n$ on-Skriftuurlike mensbenadering.

Panteïste en Spiritualiste ontken die bestaan van God wat hemel en aarde geskape het. As daar in alles god en gees moet wees, sal almal en alles goed wees, sonder sonde. Die ontkenning van die sondigheid van die mens maak dit ook onmoontlik vir 'n kind om te aanvaar dat hy nie volmaak is nie en ook net sekere vermoëns ontvang het. Sodanige opvoeding lei tot 'n gebrekkige selfbeeldbeskouing wat weer lei tot ander probleme in die onderwys. Daar kan dus by die NAB nie sprake wees van 'n Skriftuurlik-gerigte opvoeding nie.

Die beskouing dat die onderwyser slegs 'waarnemer' moet wees en moet besluit wanneer die kind moet leer en wanneer nie, herinner aan die Naturalisme en die beskouing van J.J. Rousseau oor die onderwyser. Daar kan egter nie aanvaar word dat die kind sy eie leermeester kan wees sonder die voorbeeld van 'n gesagsfiguur nie. Dit sou meebring dat gesag ontken word, asook die voorbeeld van 'n gesagsfiguur wat veral vir die klein kind van belangrike vormende waarde is.

'n Positiewe punt in die NAB-benadering is dat die onderwyser die openheid moet hê en ruimte moet skep vir kreatiewe ontwikkeling by die kind, solank die openheid geskied in balans met die leiding en voorbeeld van 'n gesagsfiguur. Opvoeding impliseer begeleiding van die onvolwassene.

\subsection{Die leerling en die skool (vergelyk 3.6)}

Reïnkarnasie is vir die Christenopvoeder onaanvaarbaar, te meer nog die vermoë van die mens om sy lot in die lewe hierna te kan bepaal deur sy lewe op aarde. Die geloof in die genade van God is die enigste wyse waarop eie onvolmaaktheid en sondigheid maar ook individuele en dus unieke talente aanvaar en begryp kan word.

Die Christen kan ook nie saamstem met evolusionisme wat God as skepper en onderhouer van die heelal ontken nie. Dat daar wel ontwikkeling en aanpassing by elke spesie (ook die mens) was en is, moet aanvaar word. 'n Dualistiese godsbeeld kan egter by die leerling ontwikkel indien God in die een asem as Skepper voorgehou word, maar andersins verkondig word dat die mens ontwikkel het uit ander wesens.

'n Mistiese wetenskap staan lynreg teenoor die algemene bewysbare wetenskappe waarmee die leerling daagliks in die klaskamer te doen kry. Die ontwikkeling van 'n mistiese wetenskap ontken noodwendig die praktiese, bewysbare feite en lei weer eens tot die ou stryd tussen irrasionalisme en rasionalisme, of in hierdie geval 'n geestelike irrasionalisme en rasionalisme. Vir die Christenonderwyser is 
die belangrikste uitgangspunt die ontwikkeling van die mens as 'n geheelwese en nie die oorbeklemtoning van die geestelike bestaan soos dit in hierdie geval na vore kom nie.

Transpersonale onderwys is dus nie vir die Christen ' $n$ aanvaarbare onderwysvorm nie (vergelyk 4.1 tot 4.6).

\section{Gevolgtrekking}

Die gevolgtrekking kan gemaak word dat die NAB-onderwys net ' $n$ verdere verdieping is van die ontwikkeling van 'n Neo-humanistiese onderwys. Die Neohumanistiese onderwys propageer ook die gevoel of irrasionele van die mens, terwyl die NAB-onderwys verder gaan deur ook die geestelike bestaan van die mens daarby te voeg en te verhef tot die een en al. Dié gevolgtrekking beteken dat die mens in die poging om homself as outonome god van sy eie lewe te verhef, in werklikheid gereduseer word tot een funksie, naamlik die geestelike. Al die ander funksies wat in 'n gebalanseerde benadering in die onderwys gelyktydig ontwikkel moet word, word dus afgeskeep. Daar moet dus tot die finale gevolgtrekking gekom word dat transpersonale onderwys soos deur die NAB gepropageer, nie 'n gebalanseerde en Skriftuurlik-getroue benadering in die onderwys is nie.

\section{Bibliografie}

BURBACK, H. 1987. School Leaders: New Kinds of Thinking Needed to Lead Education into New Age. NASSP'Bulletin, 71 (502):1-7. Nov

CHANCE, P. 1986. Teaching Thinking. ('urriculum Report of the National Association of Secondary School Principals. Virginia : Review Literature

DRECKMEYR, M. 1991. 'n "New Age" blik op die skool en skoolonderwys. Pretoria OVSA Monografie, UNISA

FERGUSON, Marilyn 1987. The Aquarian Conspiracy: Personal and Social Transformation in Our Time. Los Angeles: J.P. Tarcher.

HAHN, CAROLE L. 1984. Promise and Paradox: Challenges to Global Citizenship. Social Education, 48 (4):240-243. April.

Jenkinson, E.B. 1988. The New Age of Schoolbook Protest. Phi Della Kappan, 70(1):66-69. Sept.

MATRIANO, ESTELA 1987. Global Community Education: A Curriculum Trend for the '80s. WC.C. Fiorum, 1 (1):66-72. Jun.

MATZKEN, R.H. 1990. New Age Handboek. Anısterdam : Buijten \& Schipperheijn

PELlETTIRI, L. 1977. Writing for the Whole Person: A Transpersonal Approach to Freshman Composition. San Diego : Charka Four.

PYPERS, A. 1990. New Age bemoeilik die werk onder die Hindoes. Kerkbode:7. Jul.

SCHAEFFER, F.A. 1972. The New Super Spirituality. Downers Grove : Inter-Varsity Press

SPANGLER, D. 1984. The Rebirth of the Sacred. London : Gateway

STEYN, Jeannette. 1990. Die onderwysbenadering van enkele neo-humanistiese denkers Koers, 55(2):221-234. Jun 
STEYN, Jeannette. 1992. Studiegids vir Opvoedkundestudente in die Fundamentele en Historiese Opvoedkunde. Vanderbijlpark: Vaaldriehoekkampus van die PU vir $\mathrm{CHO}$.

VAN DER WALT, B.J. 1990. Die "New Age"-Beweging: 'n Onskuldige eksentrisiteit, nuwe hoop, demoniese sameswering of duidelike uitdaging vir die Christen? (In Die "New Age"-Beweging. The "New Age" Movement. Potchefstroom : IRS/PU vir CHO p. 132.)

VAN DER WALT, M.F. 1991. Die New Age-Beweging: 'n Studiestuk vir studente in die Wetenskapsleer. Vanderbijlpark : Vaaldriehoekkampus van die PU vir CHO.

VENTER, J.J. 1991. 'n Filosofiese perspektief op die New Age- Beweging. (In Die "New Age"-Beweging: The "New Age" Movement. Potchefstroom : IRS/PU vir CHO. p. 5174.) 